\title{
Joel Peter Witkin: Uma produção pluralista nas artes
}

Joel Peter Witkin: A Pluralistic production in art

por Marina Martins Amaral

\section{RESUMO}

Este artigo tem como objetivo fazer uma reflexão sobre a temática pluralista na obra do Fotografo Joel Peter Witkin, assim como destacar seu diferente método de produção artística. Sua obra explora temas polêmicos e inerentes ao próprio ser humano como: Religião, sexualidade e morte. 0 texto a seguir mostra que é a partir da estética grotesca e de um olhar artístico e contemporâneo que Witkin vai construir suas singulares fotografias.

Palavras-chave: Joel Peter Witkin, Pluralismo, Grotesco.

\section{ABSTRACT}

This article aims to reflect pluralist theme in the work of Photographer Joel Peter Witkin, as well as highlight his different method of artistic production. His work explores controversial issues, inherent to the human being as Religion, sexuality and death. The following text shows that it is from the grotesque aesthetic and artistic and contemporary look that Witkin will build his unique photographs.

Key-words: Joel Peter Witkin, Pluralism, Grotesque. 


\section{Joel Peter Witkin: Uma produção pluralista nas artes}

Nascido em 1939, Joel Peter Witkin é um fotógrafo norte-americano que tornou-se conhecido por sua estética singular, criando imagens polêmicas a partir do grotesco. Muitos de seus temas são reflexos de conflitos ou experiências pessoais. Para o fotógrafo a obra é uma extensão de sua vida, onde ele cria um mundo paralelo. A temática religiosa é uma constante em sua obra, sempre mostrada de forma contestadora. 0 maior impulsionador neste sentido foi a separação de seus pais quando criança, devido a incompatibilidade de crenças e a impossibilidade de lidar com suas diferenças religiosas.

Sua curiosidade e fascínio pelo não convencional são características que se mostram presentes desde sua primeira experiência fotográfica, quando aos dezessete anos retratou um rabino que acreditava ter visto e conversado com Deus. Logo após ao rabino visionário, Witkin continua explorar outros temas curiosos, sua segunda experiência vai ser em um "Show de Horrores" onde fotografa um hermafrodita. Seu interesse pelo diferente leva-o a ser designado para documentar fotograficamente as mortes acidentais ocorridas em treinos militares. Nesta época Witkin endureceu-se completamente em relação a morte.

Witkin desenvolve uma linguagem fotográfica própria com a combinação de ícones religiosos, corpos defeituosos, símbolos sadomasoquistas e pedaços de corpos humanos, meticulosamente e artesanalmente acabados, tornando assim, cada fotografia única. Sua abordagem incomum sobre temas clássicos causa desconforto e proporciona as mais diferentes reações ao público. Seus modelos exibem corpos deformados, fora de qualquer padrão de beleza aceito pela sociedade. Para muitos, o trabalho de Witkin é um grande "Freak Show" moderno, onde figuras marginalizadas como anões, transexuais e hermafroditas, através da lente da máquina, transformam-se em protagonistas de cenas mitológicas e religiosas.

Mas o que causa maior tensão e repulsa aos espectadores é sua obsessão pelo uso de cadáveres em suas composições, assim como pedaços de corpos humanos e corpos animais, quase que obrigando aqueles que a observam aceitar tal brutalidade. 0 trabalho de Witkin centra-se nestes corpos excluídos da sociedade mostrando-os em sua condição mais degradante e assustadora, assim fazendo uma crítica estética e exigindo a atenção daqueles que o observam. Seu trabalho vai além da provocação mostrando sem qualquer tipo de reserva ou pudor que é possível produzir algo belo e grotesco simultaneamente. 


\section{Joel Peter Witkin: Uma produção pluralista nas artes}

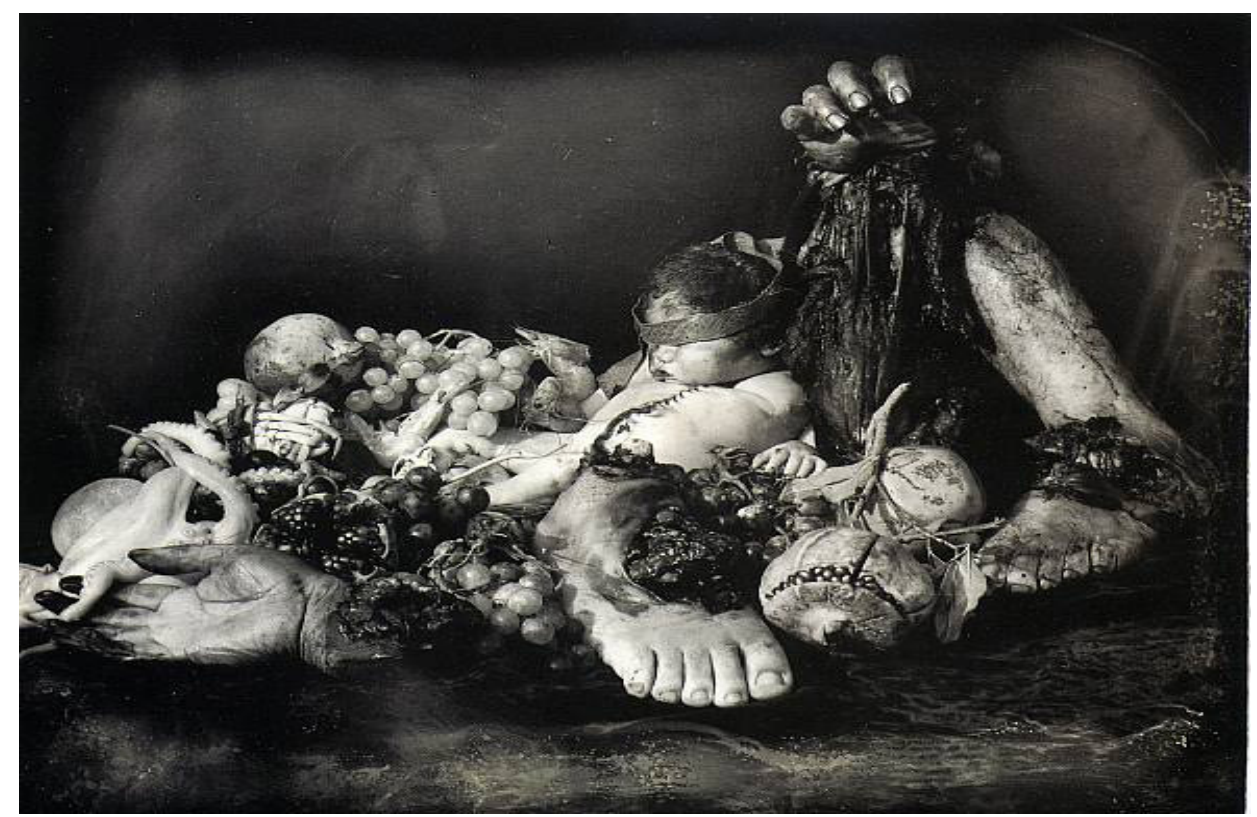

Joel Peter Witkin - Still Life with Mirror (2003)

Em sua primeira exposição individual em Nova Iorque, em 1980, torna-se imediatamente foco das atenções. Witkin ao mesmo tempo em que recebe elogios sobre a profundidade temática de sua obra, que retrata a dor e a morte com referências clássicas, é também atacado pela crítica e considerado um mestre sensacionalista, além de deturpador e blasfemo. Para o público a maior dificuldade em relação ao trabalho do artista foi, e é, ultrapassar a barreira da repulsa visual, afinal, o olhar tende a desviar-se diante da assustadora imagem, causando uma espécie de "náusea estética".

Porém, este comportamento diante de temas como a morte é muito comum, e não somente exclusivo do trabalho de Witkin. Ao mesmo tempo em que sabemos que a morte existe e que este é um destino do qual nenhum de nós esta livre, para muitas pessoas é difícil assimilar o término da vida, e mais ainda, de materializar isto de forma tão concreta como faz Witkin. A morte é um fenômeno natural em que compreende o cessar da consciência no momento em que o cérebro para de executar suas funções, porém o homem desde de o início dos tempos a encara com misticismo, magia, mistério. Não entraremos aqui nas questões de religião ou credo, pois o que estamos discutindo é a forma com que causa ojeriza e medo a imagem do corpo sem vida.

Mas imagens do repugnante também podem seduzir. Todos sabem que não é mera curiosidade que faz o trânsito de uma estrada ficar mais lento na passagem pelo local onde houve um acidente horrível. Para muitos, é também o desejo de ver algo horripilante. Chamar tal desejo de "mórbido" sugere uma aberração rara, mas a atração por essas imagens não é rara e constitui uma fonte permanente de tormento interior.(SONTAG, 2003).

Mórbida. Este foi um dos adjetivos usados para descrever a obra de Witkin, classificada como ultrajante e condenada por explorar demasiadamente a morte. Ao ser questio- 
nado sobre onde começou seu interesse por cadáveres e sua curiosidade pela morte, witkin responde que tudo começou aos seis anos de idade, quando presenciou um acidente de carro em frente a sua casa, onde uma menina morreu decapitada. Witkin conta que:

It happened on a Sunday when my mother was escorting my twin brother and me
down the steps of the tenement where we lived. We were going to church. While
walking down the hallway to the entrance of the building, we heard an incredi-
ble crash mixed with screaming and cries for help. The accident involved three
cars, all with families in them. Somehow, in the confusion, I was no longer hol-
ding my mother's hand. At the place where I stood at the curb, I could see so-
mething rolling from one of the overturned cars. It stopped at the curb where
I stood. It was the head of a little girl. I bent down to touch the face, to spe-
ak to it -- but before I could touch it someone carried me away' (WITKIN, 2001)

Encontramo-nos, já a algum tempo, em um período em que a crítica da arte encontra-se em crise. Segundo o artigo A estranha 'fala' da arte contemporânea e o ensino da arte, Anita Koneski diz que "A arte contemporânea apresenta uma crise de leitura, não apenas para os professores de arte, mas para espectadores comuns e para o próprio crítico de arte. Perguntar: o que é arte hoje? Implica, a meu ver, colocar o indagado diante do abismo. 0 que é arte hoje? Como ler a arte hoje? Para que serve a arte hoje?"(KONESKI,2009). Ao refletir sobre esta crise que Koneski se refere, percebemos que não há mais distinção de categorias, pintura, escultura, desenho, gravura, fotografia, instalação, todas completam-se e confundem-se no diálogo artístico. Também percebemos que não existem regras claras ditando os padrões estéticos, como ocorria nas vanguardas, um artista hoje não classifica-se mais em Cubista, Dadaísta ou Surrealista, dificultando assim a critica pois não há modelos ou normas a serem respeitadas pelos artistas. É neste espaço multi-engendrado e de pluri-facetas que Witkin desenvolve seus temas e compreende seu processo artístico. A poética do trabalho deste artista instiga a reflexão e provoca um diálogo diferente com o mundo, potencializando reflexões. Suas ideias liberais causam conflitos não só aos críticos, mas também a todos que exercem o olhar sob sua obra.

Apesar de inovar e produzir imagens únicas dentro de um contexto atual e pluralista, Witkin aborda temas que manifestam-se recorrentemente nas artes desde sua existência, morte, religião, sexo, padrões estéticos. 0 fotógrafo faz uma leitura crítica da beleza artificial e padronizada, mostrando o grotesco nos tempos modernos, sempre utilizando como referências a pintura e a escultura clássica. Enfatiza singularmente seu ponto de vista realista com toques de humor e ironia, tendo como estímulo o trabalho de mestres como Giotto e klint.

$1 \quad$ Aconteceu em um domingo quando minha mãe estava acompanhando eu e meu irmão gêmeo pela escadaria de onde morávamos. Estávamos indo a igreja. Enquanto andávamos pelo pátio de entrada em direção a entrada do prédio, escutamos uma incrível batida junto a gritos e choros de ajuda. 0 acidente envolveu três carros, todo com famílias dentro. De alguma forma na confusão, eu não segurava mais a mão da minha mãe. No local onde eu estava perto do meio-fio, pude ver algo rolando de um dos carros que estava virado. Parou no meio-fio onde eu estava. Era a cabeça de uma menina. Eu me curvei para tocar a face, para falar com ela - mas antes que eu conseguisse tocar-la alguém veio e me levou para longe. (WITKIN, 2001) - Traduzido pela autora. 


\section{Joel Peter Witkin: Uma produção pluralista nas artes}

Assim como inúmeros grandes artistas Witkin passa por um meticuloso processo de criação. Obrigatoriamente cada fotografia começa com um esboço, que posteriormente é usado como guia, para orientação na procura dos objetos necessários para a execução da foto. 0 artista cuidadosamente escolhe o material cênico e os protagonistas, todos os detalhes são embevecidos de cuidados, pois cada pormenor é determinante para o resultado final idealizado. É um ritual de busca, uma montagem, onde cada elemento possui significado próprio e a combinação entre eles proporciona diferentes leituras.

Podemos entender melhor este ritual de busca e composição de Witkin no livro A Imagem, a Visão e a Imaginação de 1998, onde Francastel vai dizer que:

A arte figurativa não constitui, nem um ideograma nem a transposição sensível das
coisas ou de conceitos, elaborados sem a participação ativa dos artistas. Existe uma
racionalidade no modo de selecionar os elementos que se combinam em toda a obra
do imaginário, e também existe uma racionalidade nos processos de relacionar es-
ses elementos entre si, tanto no nível da ordenação, a duas dimensões, dos signos
materiais, sobre o ecrã figurativo que serve de suporte à obra, como ao nível das in-
ter-relações imaginárias que se estabelecem na altura de se ler a obra. A elaboração
da obra de arte é o produto de uma faculdade particular; o objeto estético tem um
lugar determinado, mesmo se, aparentemente, a sua intenção é gratuita(...)Logo que
o artista, ao organizar a sua obra, elimina ou recupera, ele está a seguir uma lógica
criadora. A ordem combinatória das formas, dos volumes, das cores dos sons, corres-
ponde a um racionalismo do imaginário - não menos escrito que o das ciências ma-
temáticas, ou o da retórica. o que encontramos no momento de ler a obra, é precisa-
mente essa ordem problemática; a conformidade entre os elementos e a percepção
ocasional que os sugeriu, só acontece raramente e é secundária. (FRANCASTEL, 1998)

Mas tanto o momento de pré-produção quanto o de pós-produção são delicados e determinantes. Depois de uma sessão meticulosa de estúdio, as fotos vão para o laboratório onde passam por horas de manipulação. Witkin trabalha diretamente nos negativos, e propositalmente danifica-os usando agentes químicos e ação física, como arranhões e riscos, tornando assim, cada fotografia única devido ao tratamento exclusivo. 0 arriscado método usado pelo fotógrafo exigi muitos cuidados já que manipula sem restrições os negativos, ou seja, esta é uma etapa decisiva em que pode-se perder todo o trabaIho. Witkin explica seu processo:

Actually there are three stages in my photography. The first is when I prepare myself to make a connection, with a person or with an event or with something I've seen or read. The second is when the connection takes place, when the time, the light, the arrangements allow the photograph to happen. I believe there can be only one such moment - so I rarely shoot more than one roll. The third is when I print, which to me is seeing what through the camera I only perceived. I don't want to stop at that perception, I want to re-design and re-create what I perceived. It's like expanding time. Taking the photograph is like an automatic connection between the subject and my consciousness. Between that and the printing a week may pass - or more than a week, if I'm travelling. In the darkroom I first make normal contacts and select a frame. Then I draw or scratch on that contact. Then I put the negative on the viewing box and work on the negative - the one I have 


\section{Joel Peter Witkin: Uma produção pluralista nas artes}

decided to use. In the past I've ruined some. because I don't do one scratch at a time and then check with a print, I do it all at once, sometimes it takes ten minutes, sometimes an hour. When the negative is ready for the enlarger, it looks as if it had been left all day on the highway, with cars rolling over it. Then I do the actual printing, which may take any time between a day and a week. ${ }^{2}$ (WITKIN, 1989)

Apesar de usar também o preto e o branco, em suas fotografias predomina o uso do sépia que cria uma atmosfera antiga e um tom decadente a imagem, acentuando o contraste na fotografia. 0 artista beneficia-se desta cor para exprimir a dramaticidade em todo seu potencial, desenvolvendo um cenário misterioso e profano ao mesmo tempo. 0 cenário, os objetos, a cor e suas interferências fazem com que a imagem tenha identidade e força. Witkin durante toda sua vida artística produz uma arte coesa e autônoma, sua estética tem expressão própria e instiga a interpretação dos espectadores.

É inegável que o trabalho de Witkin é chocante e que a primeira vista causa desconforto e espanto, afinal sabemos que o mostrado nas fotografias, seja este vivo ou morto, é humano, e não ficcional como as pintura de Bacon ou Coya. 0 fotógrafo ultrapassa os limites da fotografia como documentação ao mostrar cadáveres em estagio de dor, tornando assim a "realidade" ainda mais cruel, mas não podemos ser levados, ou afastados, pela superfície da composição e sim tentar compreender o significado intrínseco na obra.

A percepção da obra de arte repousa, não sobre um processo de reconhecimento, mas de compreensão. A obra é o possível e o provável, nunca é o certo. Ela é sempre ambígua, sempre susceptível de perder certos aspectos de realidade, ou de ganhar outros. A estética vem sempre primeiro; a obra de arte não apresenta a mensagem de um conhecimento, desenvolvido exteriormente a si, por imitação ou intuição, independentemente da vontade do artista. Precise-se também que esta vontade não se apresenta como um esforço consciencioso para reproduzir um modelo, mas como uma problemática. 0 que 0 artista fixa, não é o que ele viu ou apreendeu; é o que ele procura e o que ele quer revelar aos outros. (FRANCASTEL, 1998)

$2 \quad$ Na verdade há três estágios na minha fotografia. 0 primeiro é quando eu me preparo para fazer uma conexão, com uma pessoa ou com um evento, ou ainda alguma coisa que eu vi ou li. 0 segundo é quando a conexão esta feita, quando o tempo, a luz, os arranjos permitem a fotografia de acontecer. Eu acredito que pode existir apenas uma momento assim - Então eu raramente fotógrafo mais de um rolo de filme. 0 Terceiro é quando eu imprimo, que para mim é enxergar o que através da câmera eu só percebia. Eu não quero parar somente na percepção, eu quero re-projetar e re-criar o que eu percebi. É como explicar o tempo. Tirar a fotografia é como uma conexão automática entre o sujeito e minha consciência. Entre isso e a impressão pode se passar uma semana - ou mais, se eu estiver viajando. Na sala escura eu primeiro revelo o filme normal e seleciono um frame. Depois eu desenho ou arranho o filme. Coloco o negativo em uma caixa de luz e trabalho nele, aquele que eu decidi usar. No passado eu arruinei alguns porque eu não faço um arranhão por vez e imprimo para conferir, eu faço tudo de uma vez só, as vezes leva dez minutos, outras uma hora. Quando o negativo ta pronto para ampliação, parece que ele ficou o dia todo na estrada com carros passando em cima dele. Depois eu faço a impressão final, que pode levar o tempo entre um dia e uma semana. (WITKIN, 1989) - Traduzido pela autora. 


\section{Joel Peter Witkin: Uma produção pluralista nas artes}

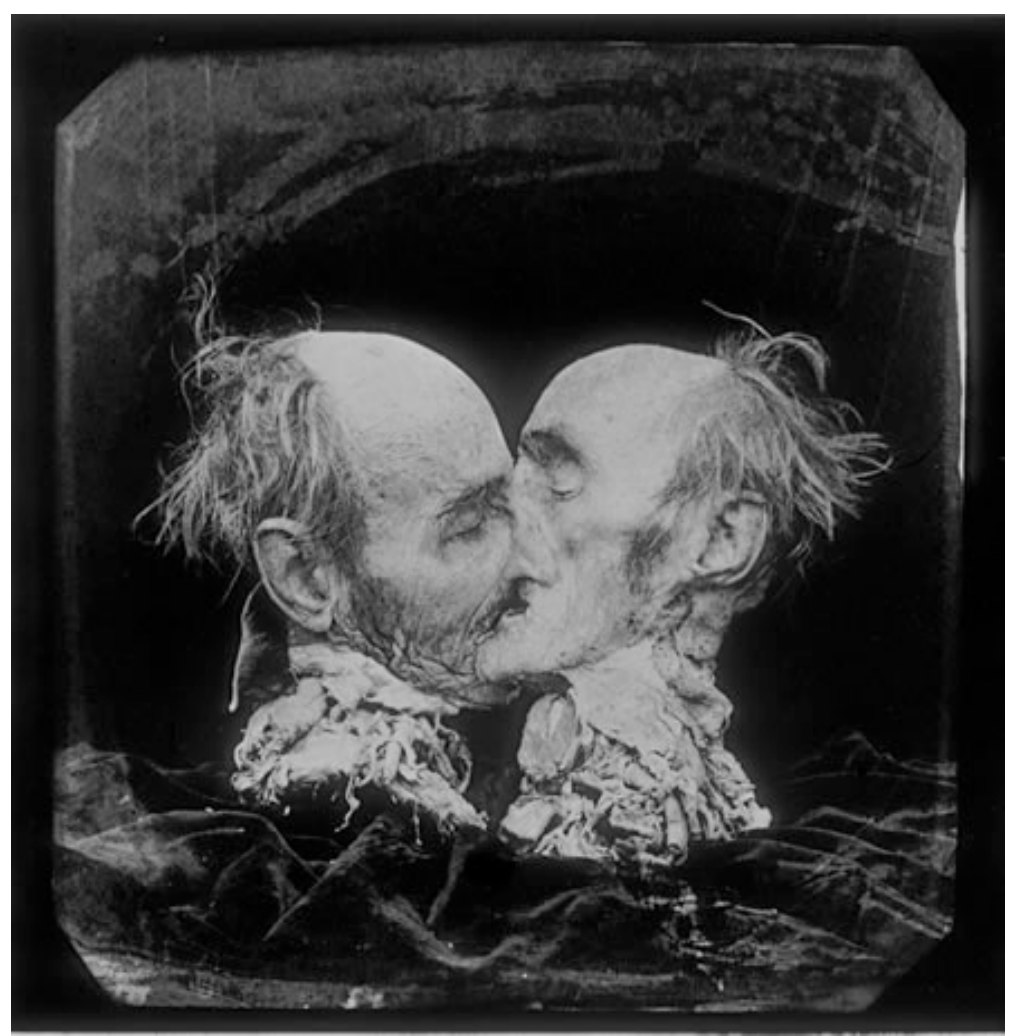

Joel Peter Witkin - The Kiss

Nem sempre o trabalho é concebido do mesmo jeito que o idealizado. No caso da fotografia "The Kiss", que a princípio deveria chamar-se The history of Spain, ao iniciar a sessão fotográfica o artista muda sua ideia original e a transforma em algo diferente "Originally I wanted to do a photograph to be called The History of Spain. When I got the box, I had no idea whether the head it contained was young or old, male or female. I had promised to return it within twenty-four hours, so I did the photograph at night and got up early to take it back. But as I was holding the two halves, I made them do this, as if kissing - and I knew that this was the image I wanted"3 (WITKIN, 1989.)

Witkin inspira-se em conhecidas obras de grandes artistas, e faz releituras destas, traduzindo- as para a sua linguagem pessoal. Podemos observar a fotografia Cods of Earth and Heaven, uma releitura do famoso quadro 0 nascimento de Vênus, nele a imagem da Vênus é transfigurada em um transexual que então personifica a musa de Botticelli. 0 título da obra vai sugerir que assim como os homens os deuses também são sensíveis as mutações e que são igualmente grotescos, desprotegidos das deformidades.

3 Originalmente eu queria fazer uma fotografia para chamar-se The History of Spain, quando recebi a caixa eu não fazia ideia se a cabeça que estava dentro dela era nova ou velha, de homem ou mulher. Eu tinha prometido devolver ela em vinte e quatro horas, então eu fiz a fotografia a noite e acordei cedo para devolve-la. Mas quando eu estava segurando as duas metades, eu as fiz fazer isto, como se estivessem beijando - se - e eu soube que essa era a imagem que eu queria. (WITKIN, 1989) Traduzido pela autora. 


\section{Joel Peter Witkin: Uma produção pluralista nas artes}

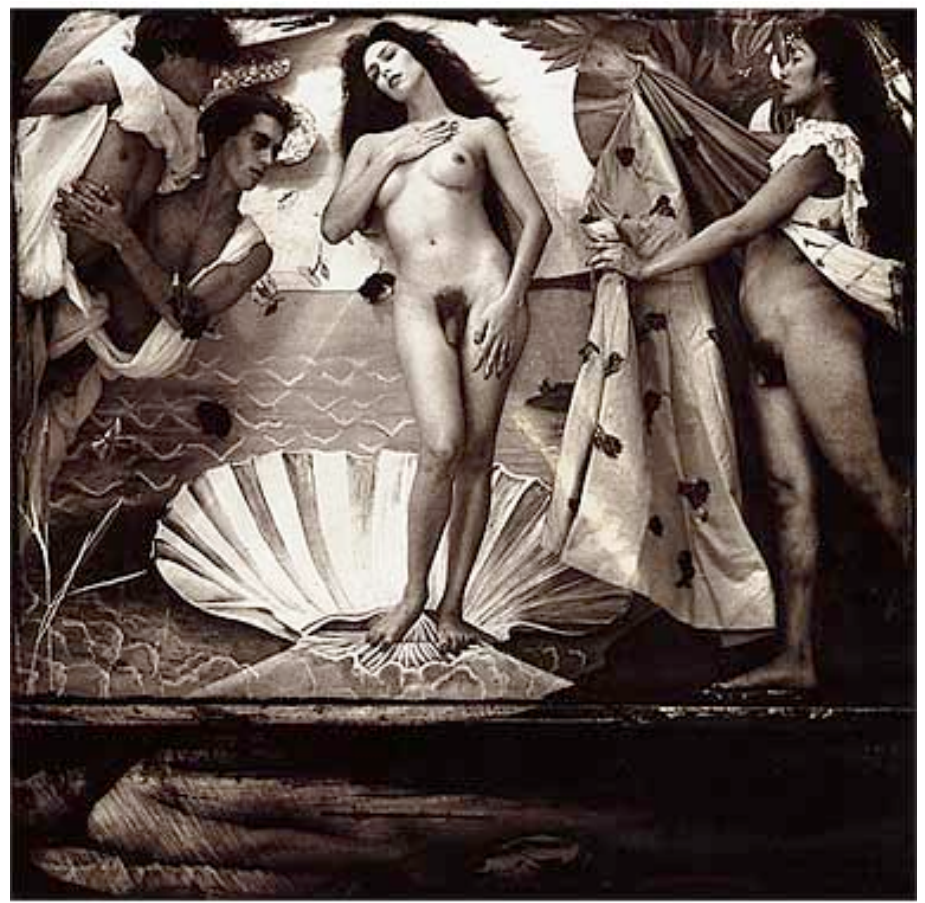

Joel Peter Witkin - Gods of Earth and Heaven (1988).

Esta fotografia, como tantas outras, de Witkin é considerada pornográfica e ofensiva, desmerecendo o valor estético e artístico implícito, Bataille diz que "0 interdito e a transgressão respondem a esses dois movimentos contraditórios: 0 interdito intimida, mas a fascinação introduz a transgressão...". Tanto a sexualidade quanto a deformidade são desconcertantes, nunca conseguimos examina-las, senti-las sem uma certa inquietação, principalmente porque todo tipo de manifestação sexual foge do padrão de convenção. Todas as formas que envolvem a representação do que se refere ao sexual, que não é relacionado com a indústria pornográfica, é vista com curiosidade e repugnância. 0 pervertido é visto como patologia na sociedade contemporânea.

Witkin tem obsessão por corpos hermafroditas e usa-os incessantemente como motivo fotográfico, como em sua fotografia de 1988, The Graces, inspirada nas varias representações das três graças durante a história da arte. Nela, ele usa três personagens hermafroditas para representar as deusas do encantamento, da beleza, da natureza, da criatividade humana e da fertilidade da dança. 


\section{Joel Peter Witkin: Uma produção pluralista nas artes}

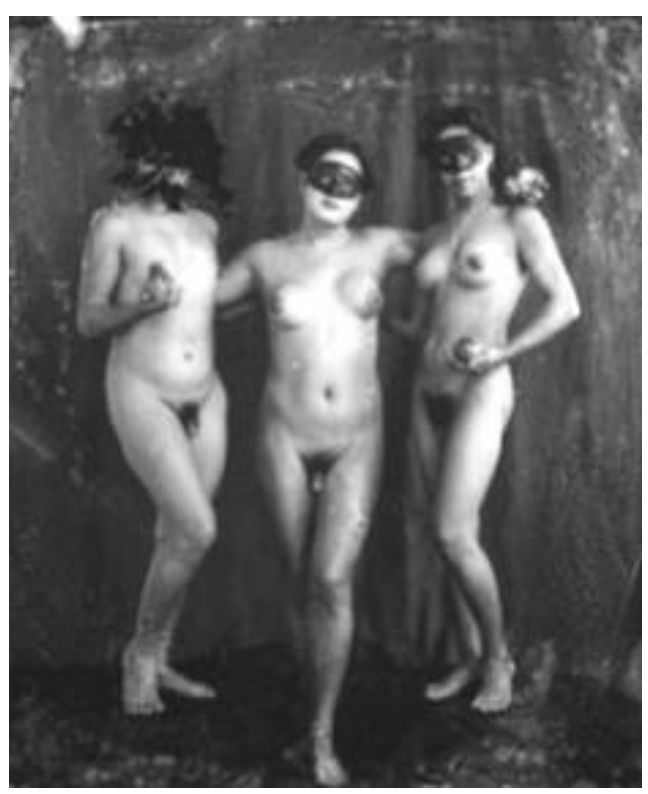

Joel Peter Witkin - The Graces (1988).

Witkin usa sua sensibilidade aguçada para retratar aquilo que é visto como mal, depravado e grotesco pela sociedade. Ele traz para dentro das galerias sua concepção de beleza, criando um mundo onde sexo, morte, religião, sadomasoquismo, coexistem com um toque de harmonia. Witkin criou uma forma de linguagem inovadora e diferente, que ao mesmo tempo prende e espanta nossos olhos. 0 artista ganhou o mundo das artes no contexto moderno fazendo sua interpretação da sociedade, dissolvendo limites através do surrealismo fotográfico. Joel Peter Witkin apresenta-nos sob perspectiva singular uma poética inovadora, distante do senso comum. É entre o depravado e o divino que encontra-se 0 artista. 0 que o diferencia de seus contemporâneos é a inquietação e o desejo de explorar aquilo que os outros tem medo. Ele desafia o lado negro, onde um vislumbre de luz é puramente autentico. Sua substancia é o maior mistério da humanidade, a questão fundamental da vida e da morte, suas análises são irrespondíveis como regra, mas possíveis de interpretações pessoais. Arte neste caso preenche as lacunas entre os sentidos e o intelecto, justificando então o porque deste tipo de linguagem. 


\section{Joel Peter Witkin: Uma produção pluralista nas artes}

\section{Referências Bibliográficas}

> BATAILLE, Georges. L’Erotismo. Editora Arnoldo Mondadori, 1976.

> ECO, Humberto. História do Feio. Portugal. Difel, 2007.

> FRANCASTEL, Pierre. Imagem, Visão e Imaginação. Portugal: Edições 70, 1987.

> KONESKI, Anita Prado. A Estranha "Fala" da Arte Contemporânea e o Ensino da Arte. Palíndromo, Florianópolis: Semestral, nćr. 2009.

> SODRÉ, Muniz e PAIVA, Raquel. 0 Império do Grotesco. Rio de Janeiro. MAUAD, 2002.

> SONTAG, Susan,. Diante da dor dos outros. São Paulo: Companhia das Letras, 2003.

\section{Internet}

> http://asclaraboias.blogspot.com/2008/04/entre-beleza-e-o-grotesco.html (Acesso em Janeiro de 2013)

> http://www.zonezero.com/exposiciones/fotografos/witkin/jpwdefault.html (Acesso em Janeiro de 2013)

$>$ http://www.horvatland.com/pages/entrevues/12-witkin-en_fr.htm (Acesso em Janeiro de 2013)

> http://www.correnticalde.com/joelpeterwitkin/ (Acesso em Janeiro de 2013)

> http://www.olhave.com.br/blog/?p=4808 (Acesso em Janeiro de 2013) 